\title{
Noticias falsas, bulos y trending topics. Anatomía y estrategias de la desinformación en el conflicto catalán
}

\section{Fake news, hoaxes and trending topics. Anatomy and strategies of disinformation in the Catalan crisis}

\author{
Roberto Aparici; David García-Marín; Laura Rincón-Manzano
}

Cómo citar este artículo:

Aparici, Roberto; García-Marín, David; Rincón-Manzano, Laura (2019). "Noticias falsas, bulos y trending topics. Anatomía y estrategias de la desinformación en el conflicto catalán". El profesional de la información, v. 28, n. 3, e280313.

https://doi.org/10.3145/epi.2019.may.13

Artículo recibido el 03-01-2019

Aceptación definitiva: 09-04-2019

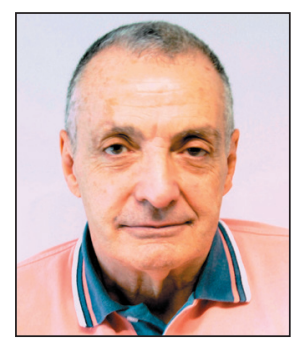

Roberto Aparici $\triangle$

https://orcid.org/0000-0002-1908-1029

Universidad Nacional de Educación a Distancia (UNED)

Facultad de Educación

Juan del Rosal, 14. 28040 Madrid, España

raparici@edu.uned.es

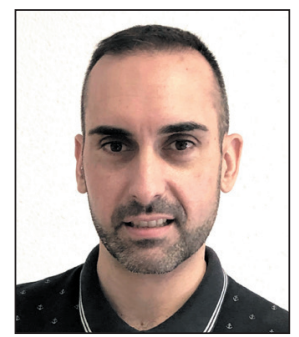

David García-Marín

https://orcid.org/0000-0002-4575-1911

Universidad Nacional de Educación a

Distancia (UNED)

Facultad de Educación

Juan del Rosal, 14. 28040 Madrid, España

dgarciamarin@invi.uned.es

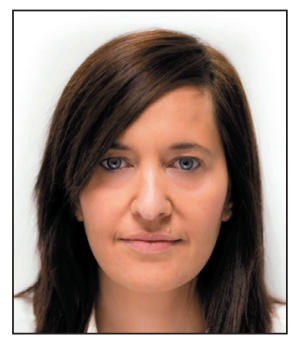

\section{Laura Rincón-Manzano}

https://orcid.org/0000-0001-7135-8104

Universidad Nacional de Educación a

Distancia (UNED)

Facultad de Educación

Juan del Rosal, 14. 28040 Madrid, España

laura.rin.man@gmail.com

\section{Resumen}

El actual ecosistema mediático ha generado nuevas formas de manipulación y desinformación, explotadas en los asuntos políticos de mayor complejidad, como fue el referéndum de independencia celebrado en Cataluña el 1 de octubre de 2017. El objetivo de esta investigación es analizar las características de las 35 noticias falsas y los bulos más difundidos en torno a este acontecimiento y realizar una cartografía de las estrategias generativas de los 80 hashtags que llegaron a ser trending topics en Twitter durante la crisis. Utilizando el análisis documental, análisis crítico del discurso y técnicas de etnografía virtual (observación no participante), detectamos que, a diferencia de las noticias falsas, los bulos fueron generados a partir de técnicas más sofisticadas y complicadas de detectar, sobre todo por la manipulación de imágenes y su utilización descontextualizada. El contrahastag, la subversión del discurso y el activismo fueron las estrategias impulsoras de las etiquetas más propagadas.

\section{Palabras clave}

Comunicación política; Posverdad; Noticias falsas; Desinformación; Bulos; Manipulación; Proceso de independencia; Redes sociales; Twitter; Etiquetas; Hashtags; Cataluña. 


\begin{abstract}
The current media ecosystem has generated new forms of manipulation and disinformation, used in political issues of greater complexity, such as the independence referendum held in Catalonia on October 1, 2017. The objective of this research is to analyze the characteristics of the fake news and the most widespread hoaxes about this topic and make a cartography of the generative strategies of the 80 hashtags that became trending topics on Twitter during the crisis. By using documentary analysis, critical discourse analysis and virtual ethnography techniques (non-participant observation), we concluded that, unlike fake news, hoaxes were generated by applying more sophisticated and complicated strategies to detect, especially due to image manipulation and their decontextualized use. Counter-hashtag, subverted discourse and activism were the catalysts for the main trending topics.
\end{abstract}

\title{
Keywords
}

Political communication; Post-truth; Fake news; Disinformation; Hoaxes; Manipulation; Independence process; Social media; Twitter; Hashtags; Catalonia.

\section{Introducción}

Desde la llegada de la web 2.0 la información se muestra accesible en casi cualquier parte del mundo de forma instantánea, rompiendo con la tradicional concepción de espacio-tiempo que configuraba la sociedad (Castells, 2001). Los medios de comunicación digitales y las plataformas sociales han hecho el mundo más pequeño, transparente e inmediato, construyendo espacios donde fluye una comunicación masiva, descentralizada y sin fronteras. Pero como contrapartida, son también canales de difusión de noticias falsas, discursos de odio y mensajes discriminatorios que perpetúan estereotipos, deshumanizan y estigmatizan a individuos y colectivos, erosionan su dignidad y reputación y desinforman a la sociedad. El nuevo ecosistema mediático se caracteriza por la sobreabundancia de información y el oligopolio de un puñado de plataformas cuyo modelo de negocio constituye el caldo de cultivo ideal para la propagación de la mentira (Aparici; García-Marín, 2018).

Por otra parte, la era de la información y la comunicación ha resultado ser la de la emoción. El ser humano es movido por las historias que le provocan emociones y éstas le empujan a la acción (Berger, 2016), independientemente de si tales relatos son verdaderos o no. En este contexto, emerge el concepto de posverdad para definir aquellas situaciones en las que los hechos importan menos que los llamamientos a la emoción y la creencia personal. Afirma Ibáñez-Fanés (2017, p. 32) que

“la posverdad no es el viejo perro de la propaganda y la mentira, o de la ocultación y el secreto propios de la política, armado ahora con un collar nuevo, sino que realmente estamos hablando de otra cosa. Este ciudadano que sólo lee y escucha lo que le gusta oír y escuchar es la contraparte, se entiende, del político que no se preocupa de si lo que dice es verdad o mentira, sino sólo de si complacerá a los suyos, a su público".

La posverdad se encuentra en el declive de los medios tradicionales y en el auge de los falsos medios digitales interactivos, en las campañas electorales, en los grupos de presión a los políticos, en los gobiernos y parlamentos, en la negación de la ciencia, en el rastro digital de los usuarios y en sus sesgos cognitivos. La posverdad es una programación, una codificación del mundo que coloca al ciudadano en la tesitura de jugar al like y al retweet y compartir los contenidos sesgados y falsos que inundan cada día sus espacios virtuales. El individuo se configura como un jugador seducido por la promesa de la participación en una partida global donde su voz casi nunca resuena con fuerza, pero donde sus actos tienen valor político y económico que rentabilizan las elites tecnológicas.

En los últimos años las investigaciones acerca de la posverdad y la circulación de fake news políticas se han centrado casi exclusivamente en el servicio de microblogging Twitter. Tal es el caso de los estudios de Conover et al. (2011) sobre polarización en esta red social, de Esteve y Borge (2018) sobre la generación de cámaras de eco en la acción comunicativa de los parlamentarios catalanes, o de Colleoni, Rozza y Arvidsson (2014) sobre nichos ideológicos en la política estadounidense. Del mismo modo, se centran en esta red social otras investigaciones sobre la polarización del debate político en España (Bustos-Díaz; Capilla-del-Fresno, 2013) y sobre la construcción de la conversación en redes de afinidad (Santoveña-Casal, 2017). Asimismo se han realizado estudios sobre interacción comunicativa entre bots y humanos (Murthy et al., 2016), patrones de difusión de la información (Rattanaritnont; Toyoda; Kitsuregawa, 2012), utilización de cuentas automáticas en las elecciones presidenciales estadounidenses de 2016 (Shao et al., 2017) y difusión de noticias falsas (Vosoughi; Roy; Aral, 2018). Más específicamente, el conflicto catalán también ha sido analizado en Twitter por Pérez-Curiel y García-Gordillo (2018).

El común denominador de estas investigaciones se sitúa en la viralización de la información, la interacción de los usuarios con los contenidos, la generación de burbujas informativas (Pariser, 2011) y la escasamente lograda bidireccionalidad del debate entre gobernantes y ciudadanos. Sin embargo, encontramos un déficit de estudios centrados en las características formales y las estrategias productivas de las informaciones falsas y los bulos más difundidos. Nuestro estudio, que parcialmente también se elabora en el espacio virtual de Twitter, pretende conocer cuáles son los patrones constitutivos más comunes de la desinformación en política a partir de una perspectiva más amplia incorporando un corpus de informaciones falsas, tanto noticias como bulos, generadas también desde los medios de comunicación. 
Focalizamos nuestro análisis en el conflicto catalán por ser el asunto de carácter político más relevante en el Estado español del último lustro. A finales de octubre de 2015 se inició la XI Legislatura del Parlament de Catalunya con el registro de una propuesta, que más tarde sería aprobada, en la que se instaba a

"declarar solemnemente el inicio del proceso de creación del estado catalán independiente en forma de república".

En virtud de la legislación española vigente, la declaración fue recurrida por el Gobierno español y suspendida cautelarmente por el Tribunal Constitucional. En 2016 el pleno del Parlament aprobó una moción reivindicando la vigencia de la declaración independentista anteriormente anulada. En septiembre de ese año, el presidente de la Generalitat, Carles Puigdemont, se sometió a una moción de confianza debido a la no aprobación de los presupuestos autonómicos de ese año. En el discurso de la cuestión de confianza, el presidente catalán anunció que el Gobierno autonómico organizaría un referéndum independentista vinculante en septiembre de 2017, ofreciendo al Gobierno central la posibilidad de una consulta acordada. El 9 de junio de 2017 se oficializó la celebración del referéndum vinculante sobre la independencia de Cataluña y se fechó para el 1 de octubre (1-O) con una pregunta en catalán, castellano y aranés:

“¿Quiere que Cataluña sea un Estado independiente en forma de república? Sí o No".

El 28 de agosto, la mayoría independentista del Parlament presentó la Ley de transitoriedad jurídica y fundacional de la República con el objetivo de garantizar la seguridad jurídica, la sucesión ordenada entre las administraciones y la continuidad de los servicios públicos, en lo que sería llamado "proceso de transición" de Cataluña a un estado independiente. La Ley fue aprobada y entraría en vigor en caso de una victoria del "sí" a la independencia en el referéndum. El 6 de septiembre, los grupos independentistas presentaron la Ley del referéndum de autodeterminación vinculante sobre la independencia de Cataluña. El texto fue aprobado por el Parlament tras horas de tensos enfrentamientos entre secesionistas y unionistas y suspendido poco después por el Tribunal Constitucional. Este referéndum fue declarado ilegal en España por contravenir las leyes y el orden constitucional del Estado español. A pesar de la existencia de numerosas informaciones periodísticas sobre noticias falsas alrededor de todo el proceso anteriormente descrito, especialmente en el contexto del 1-0, la realidad es que son prácticamente inexistentes las investigaciones sistematizadas a partir de métodos científicos acerca de las características de la desinformación generada alrededor del conflicto.

\section{Objetivo, metodología e instrumentos}

Esta investigación pretende analizar los aspectos formales de las noticias falsas (las publicadas por medios de comunicación digitales o analógicos) y los bulos (mensajes falsos fabricados en las redes por usuarios y/o colectivos a fin de crear un determinado estado de opinión) que circularon en torno al referéndum de independencia catalán del 1-O y durante los meses posteriores, así como construir una cartografía de las estrategias generativas de los hashtags (etiquetas) que llegaron a ser trending topics en Twitter durante ese período de tiempo.

Al margen de la investigación practicada sobre noticias falsas y bulos, consideramos interesante el estudio del origen de los hashtags por su papel como vehículo transmisor de gran parte de la desinformación propagada en esta red social y por su capacidad para situar a la opinión pública en nichos ideológicos, de forma que cada bando del conflicto (partidarios de la independencia y defensores de la unidad territorial del Estado español) tiende a participar elaborando y compartiendo mensajes utilizando las etiquetas más alineadas con su visión del procés. El

Los hashtags actúan no sólo como vehículos transmisores de gran parte de la desinformación propagada en Twitter, sino que también enclaustran a la opinión pública en nichos ideológicos estudio del origen de los hashtags resulta ciertamente útil, ya que funcionan no sólo como marcadores del contenido que fluye en Twitter, sino también como símbolo de pertenencia a una comunidad virtual de usuarios (Yang, 2016) donde la desinformación se comparte de manera acrítica. El hashtag como objeto de estudio presenta una amplia trayectoria en el campo de la investigación sobre el activismo comunicacional en las redes desde el punto de vista feminista (Clark, 2014; Jackson, 2016; Horeck, 2014; Williams, 2015; Khoja-Moolji, 2015; Stache, 2014), desde la lucha por los derechos de las minorías raciales (Bonilla; Rosa, 2015; Sharma, 2012) y desde el campo de la comunicación política (Bode et al., 2015).

Nuestra metodología de trabajo tuvo un carácter cualitativo ejecutado a partir de la triangulación de los siguientes instrumentos de recolección de datos:

- Análisis documental practicado sobre las noticias falsas y los bulos que circularon en torno al referéndum de independencia celebrado en Cataluña el 1 de octubre de 2017. El marco temporal aplicado a la recolección de este tipo de informaciones fue desde agosto de 2017 hasta abril de 2018.

- Análisis crítico del discurso aplicado a las noticias falsas y los bulos anteriormente referidos.

- Etnografía virtual a partir de la observación no participante de los hashtags vinculados al conflicto que fueron trending topics (TT) en la red social Twitter entre septiembre de 2017 y marzo de 2018.

Rosado-Millán, García-García y Kaplún-Hirsz (2014) conciben el análisis documental como el estudio de aquellas informaciones registradas sobre un soporte que proporcionan un conocimiento útil usadas cuando el objetivo es obte- 
ner datos específicos sobre un tema determinado. En el trabajo de campo con esta técnica se construyó una ficha de obtención de datos (tabla 1) formada por seis aspectos a analizar (titulares, origen, autoría, cuerpo de la información, fuentes e imágenes). Estos aspectos recogieron 14 indicadores enfocados al estudio de las características formales de las informaciones falsas generadas en plataformas digitales. Este instrumento de recogida fue aplicado a una muestra de 35 informaciones falsas (noticias y bulos) relacionadas con los sucesos acaecidos en Cataluña entre octubre de 2017 y abril de 2018. Para conformar la muestra, se utilizaron los siguientes criterios de inclusión:

- La información falsa analizada debía haber sido previamente desmentida por los medios de comunicación. En el caso de los bulos que utilizaban imágenes manipuladas o fuera de contexto, su falsedad fue comprobada por nuestros propios medios.

- Las noticias y bulos seleccionados debían marcar agenda informativa en España; es decir, tener cierta transcendencia mediática.

- Asimismo, debían cumplir el requisito de relevancia en redes sociales. Las noticias seleccionadas fueron aquellas que lograron mayor impacto en estas plataformas, según Crowdtangle, que ofrece estadísticas para conocer la cantidad de likes, comentarios y número de veces compartido de los contenidos en Facebook, a la vez que muestra el dato de impacto potencial de la información agregando el número de seguidores de las páginas de Facebook y los usuarios de Twitter que acceden a tal información. En ningún caso se tuvo en cuenta la ideología de tales informaciones para la conformación de la muestra.

Durante el trabajo de campo se observó la existencia de numerosos bulos basados en imágenes pertenecientes a sucesos acaecidos en un momento anterior, lo que hizo necesaria la utilización de software específico de búsqueda inversa de imágenes para comprobar su veracidad. A tal efecto se utilizó la herramienta TinEye, uno de los primeros buscadores inversos y el único que ordena los resultados cronológicamente permitiendo detectar cuál fue el contexto original de la imagen analizada.

Tabla 1. Ficha de recogida de datos para el análisis de las características formales de noticias falsas y bulos generados en torno al 1-0

\begin{tabular}{|l|l|l|l|l|}
\hline \multicolumn{1}{|c|}{ Titulares } & \multicolumn{1}{|c|}{ Origen } & \multicolumn{1}{c|}{ Autoría } & \multicolumn{1}{c|}{ Cuerpo } & \multicolumn{1}{c|}{ Imágentes } \\
\hline $\begin{array}{l}\text { Sensacionalismo/ } \\
\text { contenido emocional/ } \\
\text { exageración }\end{array}$ & $\begin{array}{l}\text { Nombre y tipo de } \\
\text { medio }\end{array}$ & Presente o ausente & $\begin{array}{l}\text { Tipología general: } \\
\text { descriptivo, opinativo, } \\
\text { interpretativo }\end{array}$ & $\begin{array}{l}\text { Tipología: vídeo, } \\
\text { Identificación y origen } \\
\text { meme, gif, infografía, } \\
\text { imagen estática }\end{array}$ \\
\hline $\begin{array}{l}\text { Expresiones de } \\
\text { opinión/ } \\
\text { interpretación }\end{array}$ & & $\begin{array}{l}\text { Presencia de } \\
\text { declaraciones }\end{array}$ & Origen \\
\hline $\begin{array}{l}\text { Adecuación al cuerpo } \\
\text { de la noticia }\end{array}$ & & $\begin{array}{l}\text { Confirmación de } \\
\text { la veracidad de los } \\
\text { hechos }\end{array}$ & $\begin{array}{l}\text { Presencia de conteni- } \\
\text { do manipulado }\end{array}$ \\
\hline $\begin{array}{l}\text { Errores ortográficos o } \\
\text { de otro tipo }\end{array}$ & & $\begin{array}{l}\text { Errores ortográficos o } \\
\text { de otro tipo }\end{array}$ & \\
\hline
\end{tabular}

De forma paralela se realizó un análisis crítico del discurso aplicado a la muestra de informaciones falsas y bulos. Santander (2011) justifica el análisis de los discursos que se producen y circulan en nuestra sociedad ya que permiten conocer en profundidad las acciones sociales y leer la realidad social de los procesos discursivos. Para analizar de forma crítica las informaciones seleccionadas generamos un instrumento de análisis (tabla 2) basado en las estrategias metodológicas de Van-Dijk (2015). Se divide en cuatro niveles analíticos (significados globales, significados locales, estructuras formales y nivel contextual) situados en dos planos diferenciados: el relativo al significado/texto y el formal/texto-contexto.

Tabla 2. Instrumento empleado en el análisis crítico del discurso. Elaboración de los autores a partir de Van Dijk (2015).

\begin{tabular}{|l|l|}
\hline Plano & Niveles analíticos \\
\hline Significado/texto & $\begin{array}{l}\text { 1. Significados globales. Referido a los temas de los que trata el discurso informativo analizado, definiendo -o más bien } \\
\text { infiriendo o asignando- cómo se emite la noticia. } \\
\text { 2. Significados locales. Estudio del significado literal de las palabras resultado del vínculo establecido entre quienes emi- } \\
\text { ten la noticia, en función de los modelos mentales o creencias que tengan de los acontecimientos, y de los receptores de } \\
\text { la información: } \\
\text { - Implícitos o sutiles. Informaciones que se pueden inferir de las palabras utilizadas que no se expresan explícitamente. } \\
\text { - Explícitos o directos. Informaciones evidentes que se encuentran en el texto. }\end{array}$ \\
\hline $\begin{array}{l}\text { Formal/ } \\
\text { texto-contexto }\end{array}$ & $\begin{array}{l}\text { 3. Estructuras formales. Estructuras sociales, políticas, culturales e históricas en las que tienen lugar los acontecimientos } \\
\text { comunicativos y que constituyen la lógica crítica y explicativa última del discurso y su análisis. } \\
\text { 4. Nivel contextual. Las propiedades de la situación inmediata e interactiva en la que tiene lugar el acontecimiento comu- } \\
\text { nicativo. Algunas propiedades son las de su ámbito general, su acción general, los participantes, los destinatarios, etc. }\end{array}$ \\
\hline
\end{tabular}


Para la codificación y análisis de los datos se utilizó el programa Maxqda, especializado en asistencia en trabajos de investigación cualitativa y métodos mixtos. Este instrumento facilitó el estudio de las categorías establecidas en la tabla 2 a través del etiquetado y la organización de las unidades discursivas en tales niveles analíticos y su posterior recuperación.

Por último, se aplicaron metodologías de etnografía virtual para el análisis de las etiquetas más relevantes (trending topics, TT) que circularon en Twitter entre septiembre de 2017 y marzo de 2018. La etnografía virtual parte de una visión holística que conecta lo físico y lo virtual, permitiendo explorar las interrelaciones que surgen entre la tecnología, la cultura y la sociedad (Hine, 2004). Los trending topics o tendencias emergentes son el resultado del análisis algorítmico de los tweets de más de 320 millones de cuentas activas al mes en Twitter. Constituyen una radiografía de los temas que más interesan a sus usuarios. Los tres investigadores firmantes del artículo participaron en esta parte del estudio mediante observación no participante practicada desde sus cuentas personales en esta red social. Como se indicó anteriormente, el marco temporal de la observación se desarrolló desde septiembre de 2017 hasta marzo de 2018. La información fue registrada en un cuaderno de campo para su posterior análisis. El método de observación practicado en esta fase fue descriptivo, no estructurado (adolecía de categorizaciones a priori), de campo (la observación fue realizada desde el lugar natural donde se producía la realidad observada, no desde ningún espacio diseñado ad hoc para la investigación), directo (los investigadores se pusieron en contacto con la realidad estudiada en primera persona) y en equipo.

Todos los TT analizados están incluidos en las tablas 3, 4 y 5. Para completar la muestra se realizó una búsqueda secundaria de etiquetas que no fueron TT pero cuyo análisis se considera pertinente en el marco de este estudio. Estas etiquetas incluidas en la segunda búsqueda aparecen en color rojo en las tablas anteriormente mencionadas. La muestra final se elevó a 80 hashtags. Los criterios de inclusión de los mensajes analizados en cada TT fueron: la presencia de palabras clave relacionadas con el conflicto (Cataluña, Catalunya, España, Espanya, referéndum, votar, votaciones, votacions, elecciones, eleccions, independencia, dictadura, separatistas, unionistas, unionistes, democracia, democràcia, Rajoy, etc.) y su publicación en castellano o catalán.

Tabla 3. Relación de trending topics analizados a favor de la independencia

\section{TT a favor de la independencia}

\#hispanoMola \#urnas \#VagaGeneral30 \#NadaQueCelebrar \#YaVieneRepública \#HuelgaAlFranquismo \#EnFrancoland \#vergUEnza20oct \#HelpCatalonia \#SeNecesitaRepública \#LaForçaDeLaGent \#VagaGeneral8N \#155esGolpeDeEstado \#LlibertatPresosPolítics \#ObrimLesEscoles \#HolaDictadura \#Votarem \#VagaGeneral30 \#LlibertatJordis

Tabla 4. Relación de trending topics analizados favorables a la unidad nacional

\section{TT a favor de la unidad nacional}

\#Hispanofobia \#EspañaSaleALaCalle \#NoNosCallaranCs \#OrgullososdeserEspañoles \#12octFiestaNacional \#STOPadoctrinamiento \#ConectarEspaña \#YoVotoCiutadans \#ProuPuigdemont \#ConXaviConCatalunya \#YoVotoPorEspaña \#Tabarnia \#Tabarnia4M \#LosProgresdelaSer \#FedeEtarras \#TotsSomCatalunya \#APorEllos

Tabla 5. Relación de TT analizados considerados neutros (no posicionados claramente en ninguno de los polos del conflicto)

\section{TT neutros}

\#16cParlem \#CatalanReferendum \#2Oct \#3Oct Rajoy \#4Oct \#heridasdelprocesa3n \#diálogo \#CrisisCatARV \#UnaSoluciónParaCat \#CatalaexitESP \#parlemhablemos \#MTÉxodoCat \#L6NdesafioCat \#FAQSAraQuèTV3 \#RecuperemElSeny \#DiesClauTV3 \#10oct \#CatARVincertidumbre \#110ct \#FAQSLaberintTV3 \#ARVcatLaRespuesta \#EI155ARV \#DecisiónPuigdemontARV \#DUInminenteESP \#ahorademocracia \#PuigdemontALaFugaAR \#ObjetivoBruselas \#RajoyT5 \#DebatTV3 \#CierreCampañaARV \#JornadaDeReflexión \#EleccionesCataluña \#L6NincertidumbreCat \#DiscursoDelRey \#Veus1 octubreTV3 \#GuerraCatalánESP \#10 \#10ct \#1 oct17 \#ReferendumCatalan \#Cataluna \#Cataluña \#Catalonia \#Catalunya

En términos cuantitativos, el análisis de los TT muestra que la mayoría (un 55\%) pueden ser considerados neutros por no situarse de forma evidente en ninguno de los dos polos del conflicto (tabla 6). Como puede observarse en las tablas 3,4 y 5 , gran parte de las etiquetas neutras más viralizadas proceden de la actividad de los medios de comunicación de masas, especialmente la televisión, siendo el programa Al rojo vivo de La sexta el principal catalizador de estos contenidos. Programas de este tipo activan la participación y el debate de sus espectadores a través de la propuesta de etiquetas en Twitter a fin de construir una audiencia social que se une a la conversación sobre los contenidos políticos de forma paralela al consumo del producto televisivo (audiencia audimétrica). Si nos centramos en los bloques protagonistas del conflicto, observamos una mayor prevalencia de los TT a favor de la independencia $(23,75 \%)$ frente a los partidarios del orden constitucional vigente (21,25\%).

Tabla 6. Distribución de frecuencias de los TT generados en Twitter alrededor del 1-O $(n=80)$

\begin{tabular}{|l|c|c|}
\cline { 2 - 3 } \multicolumn{1}{c|}{} & \multicolumn{1}{c|}{$\begin{array}{c}\text { Frecuencias } \\
\text { absolutas }\end{array}$} & $\begin{array}{c}\text { Frecuencias } \\
\text { relativas }\end{array}$ \\
\hline Independentistas & 19 & $23,75 \%$ \\
\hline Unidad nacional & 17 & $21,25 \%$ \\
\hline Neutros & 44 & $55 \%$ \\
\hline
\end{tabular}




\section{Análisis de los trending topics (TT)}

Nuestro estudio etnográfico detectó cuatro estrategias generativas centrales en la producción de hashtags:

- contrahashtag (producción de contradiscursos para defender las tesis propias frente a las establecidas por etiquetas ya existentes procedentes del bando contrario);

- anclaje a eventos clave (generación de etiquetas vinculadas a acontecimientos de gran impacto relacionados con el conflicto);

- subversión de mensajes (apropiación de hashtags creados desde el otro bando, a fin de anularlos o proporcionarles un significado contrario al original);

- fines activistas (etiquetas cuyo objetivo era llamar a la acción en favor de las tesis propias).

\section{Contrahashtag}

Consiste en la construcción de etiquetas como respuesta a hashtags anteriores ampliamente viralizados, a fin de elaborar una contranarrativa. Uno de los ejemplos paradigmáticos de este uso fue la etiqueta \#HispanoMola, configurada como una iniciativa de oposición al TT \#Hispanofobia. Este hashtag se basaba en un vídeo que el PP alojó en su cuenta oficial de Twitter con el mensaje "No es democracia, es hispanofobia" (imagen 1), que numerosos usuarios utilizaron para contrarrestar las tesis independentistas. \#HispanoMola fue una propuesta iniciada por @elbenegre con el texto:

"(Comença fil). No hem de donar explicacions de res, però anem a intentar-ho. Coses que ens agraden d'Espanya i que no ens treuen ni $1 \mathrm{~mm}$ d'anhelar la independència. Volen titllar-nos d'\#hispanofobia i els donarem \#hispanoMola".

Este tweet desencadenó una oleada de mensajes en la que se intercambiaban impresiones fundamentadas en los aspectos que cada usuario catalán apreciaba de España y de los españoles. Seleccionamos algunos de los tuits emitidos

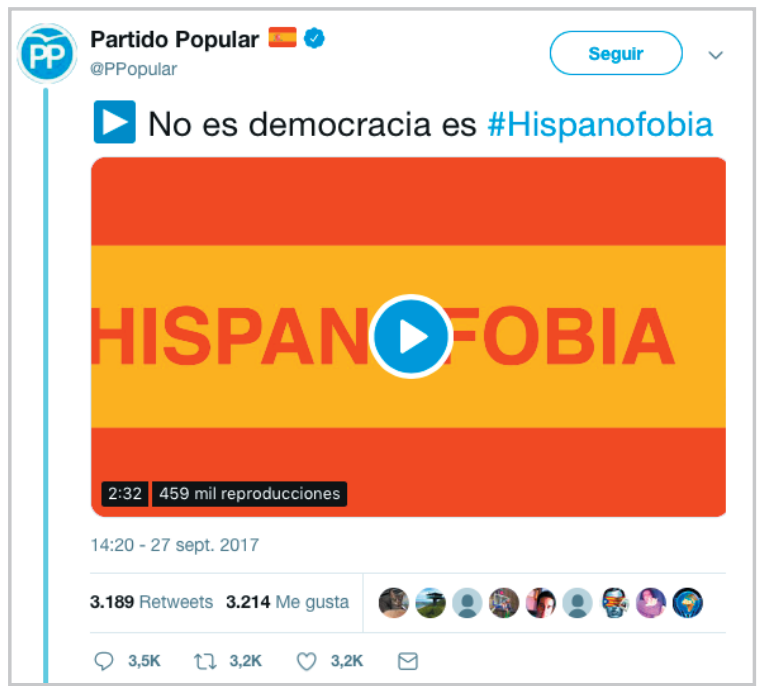

Imagen 1. Captura de la cuenta de Twitter del PP que sirvió como punto de partida al hashtag contrario \#HispanoMola. https://twitter.com/PPopular/status/913075857920548864 bajo esta etiqueta:

@montsejaraba: “La luna vino a la fragua con su polisón de nardo...” Lorca, sempre Lorca. I també Miguel Hernández i Salinas i Aute... \#hispanomola

@auvatira: Abuela valenciana, abuelo murciano. No hay \#hispanofobia Y quiero la república catalana. Sin odio ni rencor. \#hispanoMola

@ diazalmanza: Las migas, el pescaíto frito, la pringá, la meva avia Carmen (de Granada), la majoria dels madrilenys, el Prado, els vins... \#hispanoMola

@Afigue25Afigue: \#hispanoMola Catalunya está orgullosa de la cultura española. La respeta y la enriquece. Pero queremos una República y estamos muy cerca.

\section{Anclaje a un acontecimiento}

Gran parte de la información y las noticias falsas que circularon por Twitter alrededor del referéndum tuvieron como ancla un evento concreto de alto impacto, bien por configurarse como un acontecimiento multitudinario o por ejercer una marcada influencia en la vida diaria de un gran número de afectados, lo que activó una elevada participación en Twitter mediante el uso de etiquetas construidas ad hoc. Este fue el caso del hashtag \#EspañaSaleALaCalle, cuyo discurso se basó en gran medida en el apoyo de la unidad de España, el rechazo al independentismo y el apoyo a la aplicación del artículo 155 de la Constitución Española. La mayoría de los mensajes se acompañaron de imágenes de las concentraciones convocadas el 30 de septiembre de 2017 por todo el territorio nacional. Precisamente fue la movilización lo que ancló el discurso a través de esta etiqueta. Los mensajes se ilustraron también con vídeos de las manifestaciones en los que se podían escuchar gritos de "viva España" e insultos contra Mariano Rajoy y Carles Puigdemont; además en las de Madrid, sonó el Cara al sol y se realizaron saludos fascistas. Aunque no se podría afirmar la existencia de un contradiscurso, los participantes en este hashtag produjeron un relato de oposición a estas movilizaciones y resaltaron el uso de simbología franquista durante su desarrollo. 
@lafalange: Éxito en la manifestación de esta tarde. Barcelona ha sido un clamor de cánticos y banderas de España. Nada está perdido \#EspanaSaleALaCalle @conchajua

@ABenitez_Lopez: Multitudinarias manifestaciones por toda España apoyando la unidad nacional. La mayoría silenciosa no calla ni una más. \#EspanaSaleALaCalle

@12Rulipez23: Aquí los tenéis con el brazo en alto y cantando el Cara al sol. Y se cabrean si les dices fachas \#EspanaSaleALaCalle

@Catsomostodos: Barcelona respira libertad antes del intento de golpe de Estado del 1-O \#EspanaSaleALaCalle

En la misma categoría, se incluye la etiqueta \#CatalexitESP. Esta tendencia se generó tras la celebración de las juntas extraordinarias de las entidades financieras CaixaBank y Banco Sabadell en las que ambas compañías planteaban el traslado de sus sedes fuera de Cataluña ante la inseguridad que generó la previsible Declaración Unilateral de Independencia $(D U I)$, que conllevaría la salida automática de Cataluña de la zona euro. La red social se plagó de textos e imágenes que caricaturizaban este hecho.

@CaraculoMr: Para los que no entendéis el español, os resumo las palabras de Oliu (Banco Sabadell): La pela es la pela. \#CatalexitESP

@elioferran: Mucha alarma con que las empresas se irían pero nadie cuenta qué pasaría si Cataluña ofreciese una fiscalidad mejor que España \#catalexitesp

@CdV_Cantabria: El paraíso indepe está en marcha: ni bancos, ni empresas, ni turistas. Solo payeses. CATAlbania, viajando hacia el s.XIX. \#CatalexitESP

@Ferran: Cataluña hoy: sin democracia, sin libertad, sin pluralidad, sin paz, sin verdad, sin apoyos válidos, sin bancos... Seguid así. \#CatalexitESP

\section{Subversión del discurso}

Esta estrategia se fundamenta en la apropiación y masiva utilización de una etiqueta de forma alternativa y/o contraria a los objetivos establecidos por su creador. Por ejemplo, \#OrgullososdeserEspañoles fue una tendencia basada inicialmente en el título del spot publicitario que el Ministerio de Defensa publicó en YouTube para promocionar los actos organizados para celebrar el 12 de octubre, día de la Fiesta Nacional. En la práctica se utilizó para un discurso diferente. Aunque es cierto que incluyó comentarios sobre el desfile, compartiéndose imágenes de los actos militares y vídeos de los ensayos, su uso mayoritario quedó contaminado por la polarización del conflicto. Por un lado, sirvió para discutir sobre las manifestaciones convocadas en favor de la defensa de la Constitución y la unidad de España. Por otro, el relato se centró en condenar la violencia ocurrida en Cataluña con motivo de la celebración del referéndum del 1-0, a través de la publicación de fotografías, memes, gifs y vídeos de las cargas policiales acaecidas durante esa jornada. Además, se utilizó para señalar la ideología fascista de muchos tweets y el uso de simbología franquista en las manifestaciones.

@Duelelab: \#OrgullososdeserEspañoles Salimos hacia Barcelona, mañana estaremos con todos nuestros compatriotas catalanes. ¡Viva Cataluña! ¡Viva España!

@elentirvigo: 50.000 en Colón en defensa de España, sólo 1.500 en Cibeles pidiendo diálogo con golpistas \#OrgullososDeSerEspañoles

@SobresEnB: Los que vayáis a la manifestación de Colón bajo el lema \#OrgullososdeserEspañoles recordad retrasar vuestros relojes 42 años para ir acorde

@laauragandaraa: los que decían que solo había 2 o 3 franquistas, deberían entrar en el hashtag \#OrgullososDeSerEspañoles

Encontramos una variante de este modelo en el uso de la etiqueta \#Tabarnia. Este hashtag fue derivado de una iniciativa de la plataforma Barcelona is not Catalonia que propuso el nacimiento de una nueva región que incluiría Barcelona y parte de Tarragona, alejando a estas dos provincias de lo que consideraban la "amenaza separatista" (imagen 2). La campaña tuvo un origen satírico y recreaba una argumentación similar a la de los

\section{La subversión del discurso se fundamen- ta en la apropiación y masiva utilización de una etiqueta de forma alternativa $y / 0$ contraria a los objetivos establecidos por su creador}

independentistas exponiendo motivos a favor de la emancipación de este territorio de Cataluña y su lealtad al Estado español, pretendiendo ser un espejo del argumentario independentista. El carácter humorístico y subversivo inicial de la propuesta se fue diluyendo en la red social, donde los usuarios difuminaron los límites entre la broma y lo serio, adueñándose de la autodeterminación, compartiendo enlaces, eslóganes, banderas y mapas de la región sin aparente intencionalidad humorística, trasladando el debate hacia posiciones más serias.

@juansotoivars: La coña de Tabarnia perfila una posible solución: referéndum de autodeterminación en Cataluña pero por zonas, con resultado vinculante en cada zona. Si la unidad de España es irrelevante, la de Cataluña también. 
@diego_gon: Yo no tengo nada contra los payeses, simplemente los tabarñeses no somos como ellos, tenemos diferentes aspiraciones vitales y políticas. Somos cosmopolitas y educados, eso es todo. Lo de Tabarnia también lo hacemos por ellos, para que se libren del $3 \%$, de la familia Pujol etc.

@ cidcidcidcide: Puesto que Tabarnia aporta el 85\% de la economía, la futura Cataluña interior pasará a ser la autonomía más pobre de Europa Occidental, con un sueldo medio como el de Ucrania. Seguiremos siendo solidarios pero sin imposiciones.

@idalmac46: TABARNIA es una lanza clavada en el corazón del independentismo catalán. ¡GRACIAS TABARNIA!

@GuajeSalvaje: Pedimos a la comunidad internacional, y especialmente a la UE, que haga de mediadora entre la Generalitat y Tabarnia. Urgimos al diálogo bilateral para solucionar este conflicto, así como el respeto de los derechos humanos y el derecho inalienable a nuestra autodeterminación.

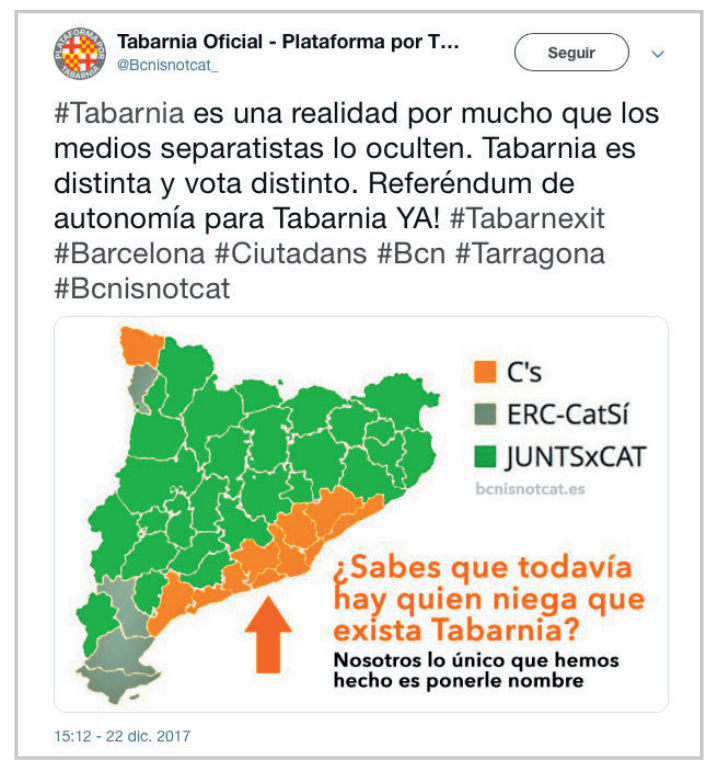

Imagen 2. Captura de la cuenta de Twitter de Barcelona is not Catolonia, impulsora de la etiqueta \#Tabarnia. https://twitter.com/Bcnisnotcat_/status/944269424390963201

\section{Activismo}

Algunos de los objetivos principales del uso de etiquetas en Twitter en situaciones de conflicto consisten en:

- visibilización de una problemática;

- realización de llamadas a la acción;

- organización de movilizaciones;

- activación de procesos de reflexión y debate a propósito de una causa.

Tales acciones de activismo estuvieron presentes en la red de hashtags generados alrededor del referéndum. El ejemplo más interesante fue Help Catalonia. Tras el ingreso en prisión sin fianza de Jordi Sánchez (presidente de la Assemblea Nacional Catalana entre 2015 y 2017) y Jordi Cuixart (presidente de Òmnium Cultural), esta última asociación, la más implicada en el procés catalán y en la organización de manifestaciones, publicó un vídeo que dibujaba una España represora y violenta. En éste aparece en primer plano una mujer que, con música emotiva de fondo, visualmente afectada y mostrando imágenes de opresión, injusticia y violencia policial, describe en inglés lo que supuestamente está ocurriendo en Cataluña y hace un llamamiento de ayuda a Europa. El vídeo centró el debate público: multitud de medios lo analizaron aplaudiendo sus virtudes o desmontando los aspectos cuestionables y falsos que presentaba, consiguiendo activar los resortes emocionales de la audiencia. El relato en Twitter se plagó de duras críticas a su evidente simplificación de los hechos y su tono apasionado y victimista. Asimismo provocó un aluvión de memes, burlas y parodias en la red social, siendo la versión andaluza del audiovisual una de las más compartidas.

@LadyPotorro: El vídeo de Help Catalonia también se le habría ocurrido a Goebbels dentro de la propaganda nazi, pero en el 42 no había Twitter.

@TxoriEspuna: España se equipara con las dictaduras. España viola tratados y derechos básicos. España tiene presos políticos. Help Catalonia

@kikerekikere: Sí, por favor HELP CATALONIA, hay que enviarles libros a mansalva, necesitan leer mucho, Historia y Derecho preferiblemente, leer, leer...

Al mismo fin sirvió \#LaForçaDeLaGent. Esta tendencia fue generada desde la Assemblea Nacional Catalana (ANC) y Òmnium Cultural (imagen 3) como acción de protesta contra la aplicación del artículo 155. El objetivo fue mover a los ciudadanos catalanes a retirar su dinero de los grandes bancos. Esta etiqueta, que se hizo mundial, se basó en la difusión de vídeos y fotografías de personas haciendo cola para acceder a un banco o sacando su dinero de los cajeros automáticos.

@FiloPolitics: Españolistas que se indignan por quién saca el dinero de los bancos, pero no les molestó el rescate ni los desahucios. \#LaForçaDeLaGent

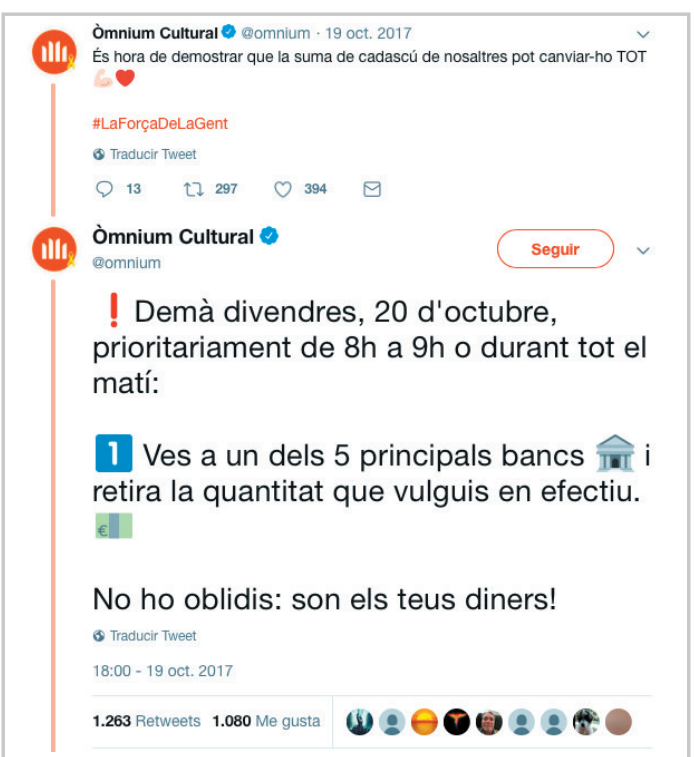

Imagen 3. Cuenta de Twitter de Òmnium Cultural Ilamando a los ciudadanos a retirar dinero de los bancos utilizando el hashtag \#LaForçaDeLaGent.

https://twitter.com/omnium/status/921103691167432705 
@ANC_Reus: Cues en algunes oficines de \#Reus per fer palesa \#LaforçaDeLaGent @CridaDemocracia @assemblea @omnium

@rmedinaTFC: 155€? Nah, 500€, que se me ha antojado comprar todo el mes en efectivo. \#LaForçaDeLaGent

@llodarga: Hoy boicot a los bancos sacando el dinero... ¿qué será mañana, comprar cava de Extremadura porque se fue Freixenet???? \#LaForçaDeLaGent

@Cazatalentos: Ellos nos amenazan con cerrar los cajeros para someternos. Nosotros retiramos nuestro dinero. ¿Y ahora qué, listillos? \#LaForçaDeLaGent

\section{La desinformación del 1-0}

\subsection{Anatomía de las noticias falsas}

En el contexto del 1-0, el uso de títulos atractivos, escandalosos o frases de opinión e interpretación de los hechos (que atraen enormemente al lector) fueron elementos comunes en las noticias falsas más propagadas en las redes. Todos los titulares versan sobre acontecimientos inéditos, novedosos, insólitos, excepcionales, curiosos y espectaculares. Algunos a su vez están desconectados del cuerpo de la supuesta noticia y no guardan coherencia con los hechos de los que se pretende informar. Esta técnica (Ilamada clickbait) define a los "titulares cebo" creados únicamente para atraer clics. Especialmente tendencioso fue el titular de la noticia "Bomberos viajaron a Bruselas dejando parques semivacíos en Cataluña". Con esta aseveración, se intentó culpar de abandonar sus puestos de trabajo a los bomberos que apoyan el independentismo de manera oficial, a pesar de explicar en el cuerpo del mismo texto que lo ocurrido realmente es que la situación de mínimos -que no parques vacíos- ocurrió solamente en 7 de los 40 existentes, circunstancia que es común en fechas como Navidad o Semana Santa. También señala el propio texto que la causa de la falta de efectivos fue debida a la no convocatoria de oposiciones al cuerpo y que los profesionales que faltaban no estaban de servicio.

Incidimos en que la muestra de informaciones falsas analizadas ha sido obtenida a partir de las noticias más ampliamente difundidas en los circuitos digitales, sin tener en cuenta su ideología. Se da la circunstancia de que un alto porcentaje de las informaciones con mayor difusión en las redes procedieron del lado unionista. Esta circunstancia no debe hacernos pensar que no existieron informaciones de este tipo por el bando independentista, aunque aquí no las consideremos debido a su menor difusión. Entiéndase que el objetivo del análisis no se centra en la realización de un estudio comparativo de las estrategias de ambos polos del conflicto, sino en examinar las características de las informaciones que experimentaron mayor propagación.

Nuestro análisis determina que las noticias más difundidas procedieron de webs conocidas por su contenido partidista, sesgado o plagado de bulos (tabla 7). Estos medios obtienen beneficios económicos a partir de la generación de tráfico en sus portales mediante la distribución de información polémica, sensacionalista, espectacular y/o falsa. En nuestro estudio son recurrentes los diarios digitales OK diario, Esdiario, Gaceta y Caso aislado. Es destacable que una de las noticias analizadas, con gruesas faltas ortográficas en su titular, (“La legión desembarca en Cataluña el 28 de Septiembre") proviene de una web llamada 12 minutos que, bajo un nombre que pretende recordar al portal de noticias 20 minutos, permite que sea el propio internauta el que fabrique la falsa información y la comparta online (imagen 4). Además estos contenidos invisibilizan su autoría. En casi todas las informaciones aparece la firma editorial (o directamente se omite todo tipo de rúbrica), lo que impide rendir cuentas a la persona que genera la información falsa.
Las noticias falsas más difundidas provienen de webs españolas conocidas por su contenido partidista, sesgado o plagado de bulos que obtienen beneficios mediante la distribución de información falsa

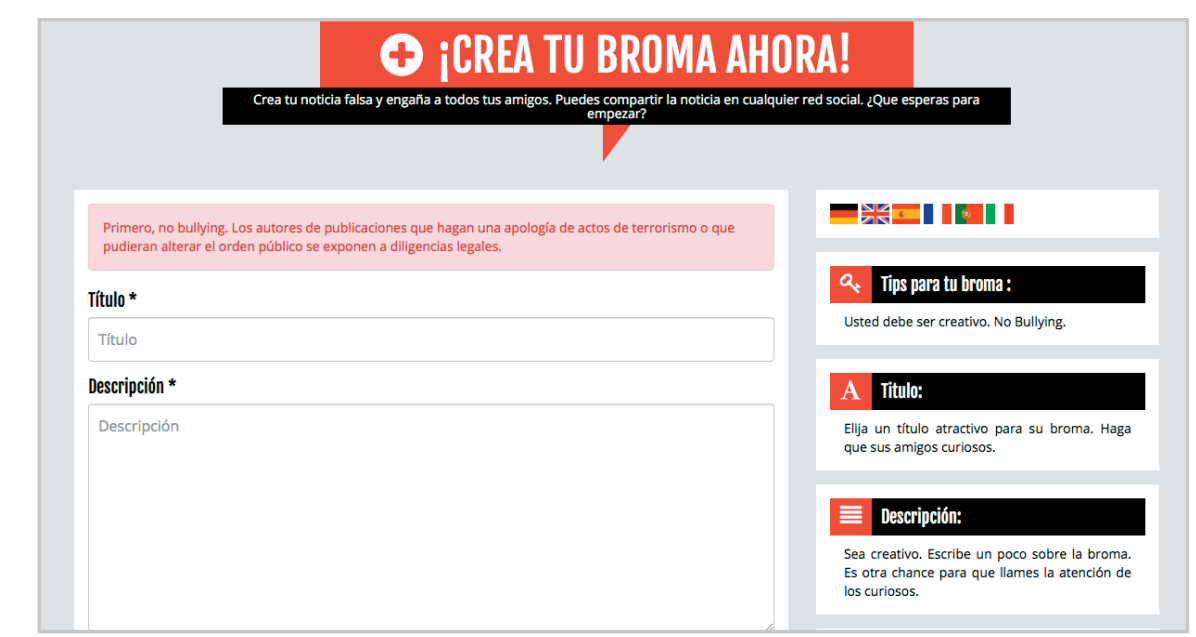

Imagen 4. Herramienta para construir noticias falsas disponible en: http://www.12minutos.com 
Tabla 7. Noticias falsas sobre el 1-O con mayor relevancia, según datos agregados de impacto en Facebook y Twitter obtenidos con Crowdtangle (última columna a la derecha).

\begin{tabular}{|c|c|c|}
\hline Titular & fecha-medio/web-firma & impacto \\
\hline La legion desembarca en Cataluña el 28 de Sptiembre & $\begin{array}{l}21 / 08 / 2017 \\
\text { http://Www.12minutos.com } \\
\text { Sin firma }\end{array}$ & 672.283 \\
\hline Primera víctima mortal en el Golpe de Estado en Cataluña: Fallece un Policía Nacional & $\begin{array}{l}\text { 03/10/2017 } \\
\text { http://www.elmunicipio.es } \\
\text { Sin firma }\end{array}$ & 65.900 \\
\hline La abuela "buenista" independentista es admiradora del terrorista Arnaldo Otegi & $\begin{array}{l}\text { 04/10/2017 } \\
\text { http://casoaislado.com } \\
\text { Sin firma }\end{array}$ & 279.983 \\
\hline Rufián se pasa de listo en un tuit, recula pero lo "capturan"y arden las redes sociales & $\begin{array}{l}\text { 07/10/2018 } \\
\text { http://www.esdiario.com } \\
\text { Sin firma }\end{array}$ & 194.901 \\
\hline La trama rusa empleó redes chavistas para agravar la crisis catalana & $\begin{array}{l}\text { 11/11/2017 } \\
\text { http://Www.elpais.com } \\
\text { David Alandete }\end{array}$ & 15.467 .713 \\
\hline Albert Rivera descobreix alarmat els Països Catalans als Ilibres de text & $\begin{array}{l}\text { 21/11/2017 } \\
\text { http://www.vilaweb.cat } \\
\text { Sin firma }\end{array}$ & 424.488 \\
\hline Bomberos viajaron a Bruselas dejando parques semivacíos en Cataluña & $\begin{array}{l}\text { 09/12/2017 } \\
\text { http://elespanol.com (Crónica } \\
\text { Global) } \\
\text { Sin firma }\end{array}$ & 250.665 \\
\hline $\begin{array}{l}\text { Los bomberos demuestran ser los mejores amigos de los "indepes": Colocan una pancar- } \\
\text { ta a favor de los golpistas en Vic }\end{array}$ & $\begin{array}{l}\text { 22/11/2017 } \\
\text { http://Www.naciodigital.cat } \\
\text { Sin firma }\end{array}$ & 471.274 \\
\hline La alcaldesa de Gerona convierte las mentiras del 1-O en un conjunto escultórico & $\begin{array}{l}\text { 24/04/2018 } \\
\text { http://www.okdiario.com } \\
\text { Sin firma }\end{array}$ & 819.530 \\
\hline
\end{tabular}

Las noticias falsas publicadas, más que describir los hechos ocurridos, exponen ideas o interpretaciones de los acontecimientos, a la vez que abordan el tema catalán desde el sensacionalismo y la espectacularización, mezclando en numerosas ocasiones informaciones falsas con noticias reales. Ninguna de las publicaciones analizadas se esfuerza en confirmar la veracidad de los acontecimientos en los que se basan. Estos textos se fabrican sin utilizar fuentes confiables. La gran mayoría se hace eco de supuestas declaraciones o fuentes sin identificar ni enlazar; además de tener como origen principal publicaciones realizadas por usuarios de Twitter, que se capturan y se adjuntan a la información con el fin de dar realismo, fuerza o credibilidad al relato. Un ejemplo es la noticia titulada "Rufián se pasa de listo en un tweet, recula pero lo capturan y arden las redes" (Esdiario, 2017), en la que se fabrica la información -sin firma- en torno a una única supuesta captura de pantalla de la cuenta del político catalán en esa red social. Asimismo es mayoritario el uso de fotografías, gráficos y vídeos para ilustrar las informaciones. Se tiende a utilizar imágenes de archivo, siendo muy escaso el uso de pies de foto.

A partir de la nominación de los actores sociales, observamos que en muchas de las informaciones falsas favorables a la unidad de España no se especifica la identidad de los partidarios de la independencia, estableciéndose procesos de generalización, indeterminación, despersonalización y deshumanización de éstos (tabla 8). Esta dinámica es más frecuente en el bando defensor de la unidad de España. La elección del léxico, en muchos casos con errores ortográficos, es accesible a todo tipo de públicos.

Tabla 8. Relación de conceptos vinculados a la nominación común de los actores sociales presentes en las noticias falsas del 1-0.

Nominación común de los actores sociales

radicales, catalanes, un policía nacional, el subinspector de la Policía Nacional, independentistas, separatistas, golpistas separatistas, la abuela "buenista", el terrorista, la independentista, etarra, el asesino, el diputado de ERC, impulsores del desafío soberanista catalán, golpistas, redes chavistas, partidos constitucionalistas, medios prorrusos, chavismo, bomberos, efectivos antincendios, prosecesionistas, "indepes", alcaldesa secesionista.

\subsection{Bulos difundidos en Twitter}

El análisis etnográfico practicado sobre las etiquetas más difundidas en Twitter ofreció un profundo conocimiento de los bulos propagados en el contexto del referéndum. La recogida de estas falsas informaciones y su análisis permite establecer una cartografía de las estrategias utilizadas en su creación. Estas técnicas fueron: falsa atribución, exageración de los hechos, manipulación de imágenes, fabricación de fake news, y suplantación de identidad (counterfeit). 


\section{Falsa atribución}

Consiste en relacionar imágenes de otros contextos, situaciones, lugares y/o momentos con los hechos acaecidos en torno al procés. Fotografías y vídeos se rescatan de otros acontecimientos para mostrar las imágenes necesarias para apoyar el relato buscado. En el contexto del 1-0, una de esas fotografías muestra a un joven con heridas de sangre en el rostro supuestamente producidas por la represión policial decretada por el Gobierno español en cumplimiento de las disposiciones judiciales en contra de la celebración del referéndum (imagen 5). Nuestra comprobación mediante herramientas de verificación de búsqueda inversa muestra que la fotografía utilizada fue tomada el 12 de julio de 2012 durante una carga policial en los disturbios provocados por una marcha minera y publicada en el portal Periodismo humano. Otra fotografía similar de un menor sangrando se atribuyó a la brutalidad policial en esa jornada cuando en realidad se trata de una captura realizada en 2012 durante unas cargas policiales de la policía autonómica catalana ante unos grandes almacenes en Tarragona. Desde el lado opuesto, también se utilizaron estas estrategias. La líder del partido UPyD, Rosa Díez, usó una imagen de la Diada de 2012 para ilustrar una manifestación en contra del referéndum.

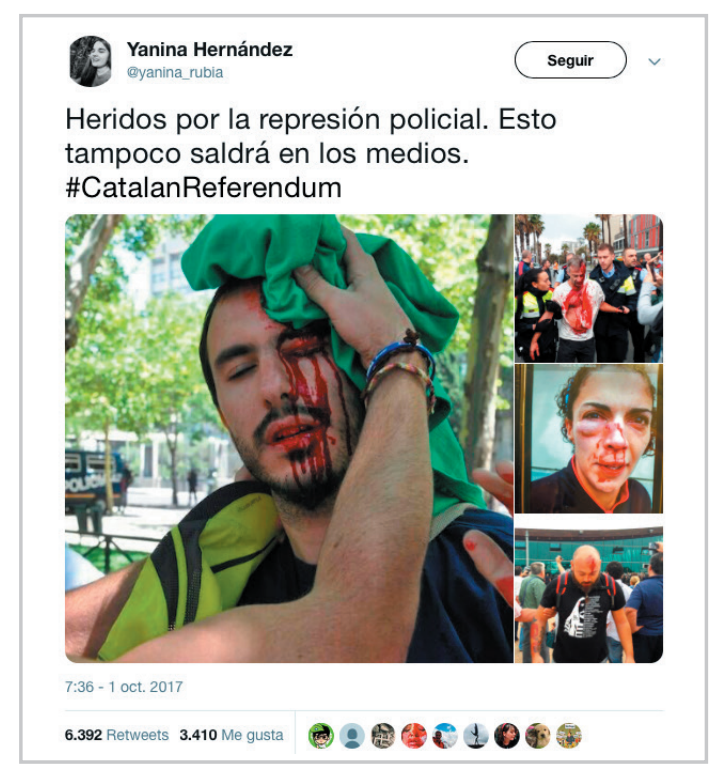

Imagen 5. Fotografía (obtenida en 2012) atribuida a los acontecimientos del 1-O. Circuló en Twitter con el hashtag \#CatalanReferendum.

https://twitter.com/yanina_rubia/status/914423839911759872

\section{Exageración de los hechos}

Algunas de las noticias que circularon la jornada de la consulta, aunque no completamente falsas, fueron exageradas para mostrar de manera reforzada la violencia de las fuerzas de seguridad contra los ciudadanos catalanes que acudieron a votar y contra aquellos que pretendían que el referéndum se llevara a cabo con normalidad. Un ejemplo fue la noticia protagonizada por una joven de 33 años, Marta Torrecilla, víctima de una agresión por parte de un policía, quien le habría ocasionado la rotura de todos los dedos de una mano. Finalmente, la propia afectada reconoció que sólo sufrió una capsulitis (inflamación de la cápsula articular), una lesión de menor gravedad que la que circuló por las redes sociales.

\section{Manipulación de imágenes}

La fotografía de cargas de la Guardia Civil contra votantes catalanes alrededor de una bandera estelada ondeando fue una de las imágenes icónicas de la jornada. La realidad es que la fotografía fue tomada el 1 de octubre, pero en la captura original no aparecía ninguna bandera, sino que ésta fue añadida a posteriori (como se demuestra en la imagen 6) con el fin de otorgar mayor carga simbólica a la composición.
Los bulos se fundamentaron en la exageración de los hechos, la utilización de imágenes procedentes de otros contextos y la suplantación de identidades

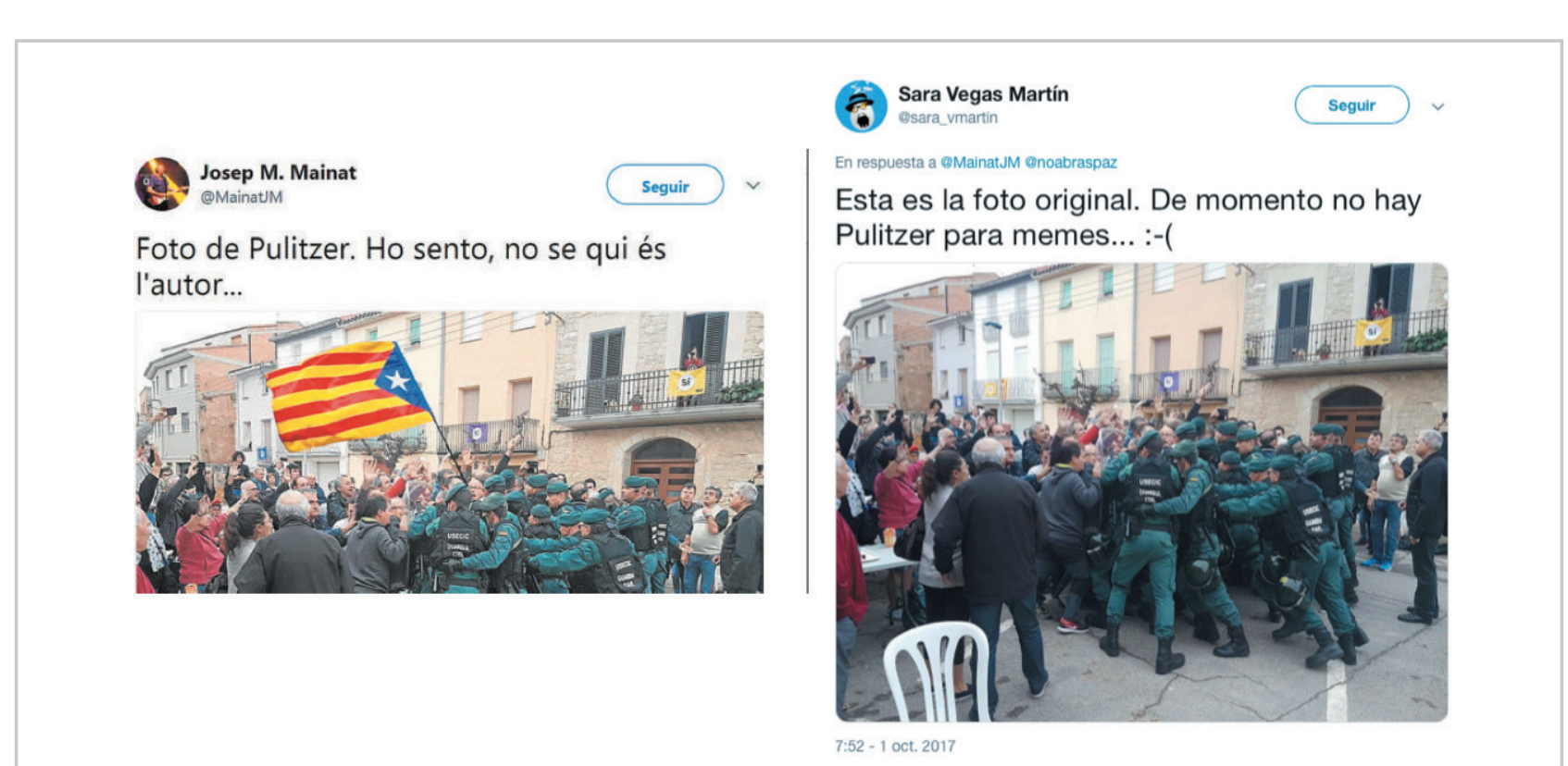

Imagen 6. A la izquierda, la fotografía manipulada con la estelada. A la derecha, la imagen original.

https://twitter.com/mainatjm/status/914402135734996993?lang=es

https://twitter.com/sara_vmartin/status/914427891018027008/photo/1 


\section{Invención de los hechos}

Son las conocidas como fake news: contenidos enteramente falsos e inventados, fabricados y propagados deliberadamente para engañar a la población con objetivos políticos y/o económicos. Utilizan tácticas de guerrilla de marketing 2.0, tales como el uso de bots automáticos para distribuir la información en redes sociales y la creación de portales web y perfiles en dichas redes con nombres -y diseños - muy parecidos a las grandes corporaciones mediáticas y a personajes muy conocidos (counterfeit), como analizaremos en la siguiente categoría. Un ejemplo lo encontramos en el tweet con el que el subinspector de la Policía Nacional, Alfredo Perdiguero, inicia el bulo del agente fallecido durante los incidentes del 1-O presuponiendo que la víctima se encontraba destacada en Cataluña con su unidad, la VI UIP de Bilbao (imagen 7). El autor rectificó su error, aunque sin eliminar el mensaje original de su cuenta, por lo que el tweet con la información falsa continuó propagándose. También fue fabricada la información ofrecida por un tweet de un usuario llamado Carlos Llopis arrogándose la legitimidad de comunicar al ministro de Exteriores estonio la declaración de independencia a fin de iniciar el proceso de reconocimiento de la república catalana por parte de aquel país. Otras informaciones falsas que se difundieron durante los meses de octubre y noviembre de 2017 fueron

- la inexistente declaración de inconstitucionalidad de la aplicación del artículo 155 por parte de la ONU (el organismo manifestó que el conflicto debía resolverse "dentro del marco de la Constitución Española");

- la falsa creación de sellos para el correo postal estonio celebrando la declaración de independencia de Cataluña (imagen 8).

\section{Suplantación de identidad (counterfeit)}

Mencionado anteriormente, el counterfeit consiste en la creación de páginas o perfiles falsos en redes sociales que imitan el diseño y la imagen corporativa de grandes marcas o suplantan la identidad de personajes relevantes.

Encontramos un ejemplo en una cuenta falsa de Twitter de la líder de la oposición en Cataluña, Inés Arrimadas, pidiendo a los manifestantes de las movilizaciones en favor de la unidad de España que "no saquen las banderas preconstitucionales delante de los periodistas". El tweet se envió desde una cuenta (@InesArrimades), eliminada posteriormente, que imitaba a la oficial de la política catalana (@InesArrimadas).

\section{Conclusiones}

Si los procesos de manipulación generados en torno al Brexit y a la elección de Donald Trump parecían ajenos al contexto español, a partir del 1 de octubre de 2017 esto cambió diametralmente. Esa jornada, y debido a internet, el conflicto catalán se transformó en un asunto mundial y Twitter en el canal de comunicación que a tiempo real y con detalle informaba sobre la violencia ejercida por los cuerpos y fuerzas de seguridad del Estado tratando de impedir la realización del referéndum, a la vez que mezclaba información fabricada o manipulada, plagada de inexactitudes y de manifiestas mentiras, acompañada de vídeos e imágenes de fechas anteriores.

En línea con los resultados de los estudios de Hernández-Santaolalla y Sola-Morales (2019) aplicados al mismo contexto, la posverdad en la crisis catalana en forma de noticias falsas y bulos basados en una constante apelación a las emociones, creencias o prejuicios de las audiencias como eje transversal, ha sido permanente durante todo el conflicto. Esta información fue utilizada como impulsora de discursos de odio, validando las mentiras como respaldo ideológico, dirigiéndose a los sentimientos de cada uno de los bandos, donde la desinformación encaja con sus propios prejuicios, con el único objetivo de persuadir y construir estereotipos sociales y realidades que refuerzan sus propios modelos mentales. Nuestros resultados confirman el constructo teórico elaborado por Coromina y Padilla (2018), basado en una conceptualización de la desinformación en el conflicto catalán desde el descrédito de los actores implicados, la amplificación 
de los hechos y la búsqueda de adhesiones a los diferentes argumentarios. Los hechos verdaderos han perdido toda validez e importancia dejando que la información falsa construya posverdades a medida. Posverdades que anuncian que

"la propia noción de verdad, y más concretamente la verdad pública, ha dejado de tener sentido. De hecho, está siendo reemplazada por la idea de que existen distintas "verdades" en el cuerpo social, sin que nada parecido a una verdad única pueda establecerse o reconocerse" (Ibáñez-Fanéz, 2017, p. 66-67).

Los relatos falsos en torno al 1-O marcaron la agenda mediática, configurando algunos de los temas a discutir y obligando a los medios de comunicación a reservar espacio para publicar los desmentidos de la multitud de bulos y rumores vertidos. Las redes se erigen como nuevos actores sociales en la configuración de la opinión pública, establecen para una gran parte de la sociedad la realidad conocida y aceptada sin necesidad de leer diarios o editoriales y sin esperar al informativo de horario fijo que marque la agenda. Todo tipo de información circula por las autopistas digitales, permitiendo que la opinión pública disfrute del mayor caudal informativo de todos los tiempos, lo que a su vez complica la ya de por si ardua tarea de separar realidad y ficción.

Con nuestro análisis hemos comprobado que gran parte de la desinformación no proviene de los grandes medios informativos tradicionales, sino que su propagación depende cada vez más de su circulación en internet y de la participación de los usuarios compartiendo y discutiendo la información. La red social Twitter fue utilizada como canal de difusión y en ningún momento como instrumento de diálogo, confirmando los estudios de Carrasco-Polaino, Villar-Cirujano y Tejedor-Fuentes (2018). En esta plataforma, las publicaciones con información falsa y manipulada que mayor repercusión tuvieron se repartieron prácticamente por igual entre las dos polaridades del conflicto. Ambos bandos usan esta red social para enunciar la propia opinión, expresar emociones y criticar a la postura contraria. En sintonía con los estudios de Pérez-Curiel y García-Gordillo (2018), estas narrativas se basan en elementos de representación como la utilización de vídeos, fotografías y hashtags, así como en la acción espontánea de sus usuarios que permite la creación rápida de contradiscursos, como los elaborados bajo las etiquetas \#hispanoMola-\#Hispanofobia o \#12octFiestaNacional-\#NadaQueCelebrar. Asimismo la sátira, que siempre ha tenido un lugar en periódicos, revistas y comentarios televisivos, tiene un gran espacio reservado también en Twitter. No es difícil encontrar tweets irónicos o sarcásticos sobre el cambio de sede social de empresas catalanas, la declaración y suspensión automática de la DUI o la huida de Puigdemont a Bruselas, que plagaron de memes esta red social. Otras técnicas generativas de las etiquetas más propagadas durante el conflicto fueron el anclaje a acontecimientos clave, la subversión de mensajes y los fines activistas.

El complejo conflicto catalán ha monopolizado la política española de los últimos años y ha abierto debates sobre el modelo territorial, el encaje de Cataluña en el Estado español, la situación del castellano en esta comunidad, la politización de la justicia y la honestidad de los medios a la hora de presentar el conflicto. Estas cuestiones han polarizado la opinión pública hasta el extremo. Las mentiras y los bulos han alimentado la generación de estos dos polos, sin apenas dejar espacio a posiciones neutrales que incitaran el diálogo reposado. Las redes sociales, nido de odio para muchos usuarios, fueron aprovechadas para extender falsedades, además de insultar, criticar y amenazar a todo aquel contrario a su pensamiento.

Las estrategias productivas de estos bulos se fundamentaron en la exageración de los hechos, la manipulación de las imágenes, la suplantación de identidades y la utilización de fotografías y vídeos procedentes de otros contextos. Confirmando las tesis de Coromina, Prado y Padilla (2018), la utilización de la imagen (vídeos y fotografías) como lenguaje mediático central para la generación de emociones tuvo un papel fundamental en ambos polos de la crisis. El manipulado de producciones fotográficas y audiovisuales resulta esencial en la fabricación de la falsedad, lo que la hace más difícil de detectar; frente a las técnicas de creación de noticias falsas, menos sofisticadas en su producción según nuestra observación. Es por ello que se requiere una elevada capacitación técnica y mediática para determinar la falsedad de materiales donde concurre algún tipo de manipulación de la imagen. El manejo de las herramientas de software necesarias para comprobar la veracidad de tales contenidos no está al alcance de cualquier usuario y en ocasiones, incluso los profesionales de la información encuentran dificultades para determinar su autenticidad. De ahí la vital importancia del refuerzo de los mecanismos de verificación de imágenes, especialmente en situaciones de conflicto y alta polarización de la opinión pública (Cea Esteruelas, 2018). No obstante, el futuro de la verificación de imágenes fotográficas y vídeos plantea incógnitas por la sofisticación en los engaños que trae consigo la inteligencia artificial (deep fakes). Afirma Redondo:

“En el pasado, la falsedad todavía podría reconocerse a cámara lenta. Sin embargo, será difícil para el ojo humano reconocer un algoritmo que convierte una escena de verano en una del invierno más total, o distinguir que en un vídeo de Barack Obama en realidad el audio y el movimiento de la boca se han añadido posteriormente" (Redondo, 2018). 
Frente a la dificultad de detectar los bulos construidos desde la edición fotográfica y audiovisual, las noticias falsas publicadas en diarios online presentan unas características que no se apartan del canon encontrado en la creación de fake news situadas en otros contextos, por lo que resultan razonablemente sencillas de detectar atendiendo a su morfología:

- uso de titulares exagerados;

- ausencia de fecha y firma;

- origen en fuentes poco fiables;

- presencia de faltas ortográficas;

- falta de pruebas que verifiquen la información.

A pesar de la aparente facilidad para detectar estas fake news, la desinformación en torno al referéndum fue ampliamente propagada por ciudadanos y partidos políticos, víctimas de sus propios sesgos cognitivos. Esto demuestra que el estudio de la comunicación no puede separarse del análisis del sistema social y que éste no puede entenderse sin comprender los fenómenos cognitivos que intervienen en las decisiones de los individuos (Castillejo, 2017). En este sentido, Chomsky y Ramonet destacan que:

"querer informarse sin esfuerzo es una ilusión que tiene que ver con el mito publicitario más que con la movilización cívica. Informarse cansa y a este precio el ciudadano adquiere el derecho de participar inteligentemente en la vida democrática" (Chomsky; Ramonet, 1995).

La arquitectura de internet hace posible la construcción de burbujas informativas que actúan como máquinas polarizadoras, ayudando a confirmar y amplificar los puntos de vista personales. Ante el aluvión de informaciones de todo tipo al que cada sujeto se ve sometido diariamente, éste se inclinará a considerar como verdaderos aquellos contenidos que minimicen todo lo posible su disonancia cognitiva, es decir acogerá como verdaderas aquellas informaciones que se ajusten más a sus creencias preestablecidas. Este sesgo de confirmación tiende a dar más peso a la información que confirma las visiones preexistentes. La anatomía de la desinformación construida alrededor del conflicto catalán nos muestra que es urgente una alfabetización crítica de la ciudadanía para no sólo detectar la falsedad que circula en las redes, sino para luchar contra los propios sesgos ideológicos que la polarización de determinados discursos activa.

\section{Referencias}

Aparici, Roberto; García-Marín, David (2018). Comunicar y educar en el mundo que viene. Barcelona: Gedisa. ISBN: 978 8417341541

\section{Berger, Jonah (2016). Contagious: Why things catch on. New York: Simon \& Schuster. ISBN: 9781451686586}

Bode, Leticia; Hanna, Alexander; Yang, Junghwan; Shah, Dhavan V. (2015). "Candidate networks, citizen clusters, and political expression: Strategic hashtag use in the 2010 midterms". The Annals of the American Academy of Political and Social Science, v. 1, n. 659, pp. 149-165.

https://doi.org/10.1177/0002716214563923

Bonilla, Yarimar; Rosa, Jonathan (2015). "\#Ferguson: Digital protest, hashtag ethnography, and the racial politics of social media in the United States". American ethnologist, v. 42, n. 1, pp. 4-17.

https://doi.org/10.1111/amet.12112

Bustos-Díaz, Javier; Capilla-del-Fresno, Lucía (2013). “Twitter y la polarización del debate político: análisis del caso \#objetivodeguindos y \#aznara3". Historia y comunicación social, n. 18, pp. 499-509.

https://doi.org/10.5209/rev_HICS.2013.v18.44260

Carrasco-Polaino, Rafael; Villar-Cirujano, Ernesto; Tejedor-Fuentes, Laura (2018). "Twitter como herramienta de comunicación política en el contexto del referéndum independentista catalán: asociaciones ciudadanas frente a instituciones públicas". Icono 14 , v. 16 , n. 1, pp. 64-85.

https://doi.org/10.7195/ri14.v16i1.1134

Castells, Manuel (2001). La galaxia internet. Barcelona: Plaza y Janés. ISBN: 8401341574

Castillejo, Miguel (2017). “Nuevos retos para el estudio de la comunicación: fragmentación de la agenda pública y cámaras de eco". Seo media lab. Estudios de visibilidad: medios y sectores económicos, 22 marzo.

https://seomedia-lab.com/comunicacion-agenda-publica-camaras-de-eco

Cea-Esteruelas, Nereida (2018). "La fotografía periodística y los social media: la jornada del 1 de octubre en Cataluña". Miguel Hernández communication journal, v. 2, n. 9, pp. 359-377.

https://doi.org/10.21134/mhcj.v0i9.260

Chomsky, Noam; Ramonet, Ignacio (1995). Cómo nos venden la moto: información, poder y concentración de medios. Barcelona: Icaria. ISBN: 9788474262452 
Clark, Rosemary (2014). "\#NotBuyinglt: Hashtag feminists expand the commercial media conversation". Feminist media studies, v. 14, n. 6, pp. 1108-1110.

https://doi.org/10.1080/14680777.2014.975473

Colleoni, Elanor; Rozza, Alessandro; Arvidsson, Adam (2014). "Echo chamber or public sphere? Predicting political orientation and measuring political homophily in Twitter using big data". Journal of communication, v. 64, n. 2, pp. $317-332$. https://doi.org/10.1111/jcom.12084

Conover, Michael D.; Ratkiewicz, Jacob; Francisco, Matthew; Gonçalves, Bruno; Flammini, Alessandro; Menczer, Filippo (2011). "Political polarization on Twitter". In: Procs of the Fifth intl AAAl conf on weblogs and social media. https://www.aaai.org/ocs/index.php/ICWSM/ICWSM11/paper/view/2847

Coromina, Òscar; Padilla, Adrián (2018). "Análisis de las desinformaciones del referéndum del 1 de octubre detectadas por Maldito Bulo". Quaderns del CAC, v. 21, n. 44, pp. 17-26.

https://www.cac.cat/sites/default/files/2018-08/Q44_ES.pdf

Coromina, Òscar; Prado, Emili; Padilla, Adrián (2018). “The grammatization of emotions on Facebook in the elections to the Parliament of Catalonia 2017". El profesional de la información, v. 27, n. 5, pp. 1004-1001.

https://doi.org//10.3145/epi.2018.sep.05

Esdiario (2017). "Rufián se pasa de listo en tuit, recula pero lo 'captura' y arden las redes". EsDiario.com, 7 octubre. https://www.esdiario.com/148613336/Rufian-tuitea-lo-elimina-pero-alguien-lo-captura-y-revoluciona-las-redes.html

Esteve, Marc; Borge, Rosa (2018). "Echo chambers in Parliamentary Twitter networks: The Catalan case”. International journal of communication, n. 12, pp. 1715-1735.

Hernández-Santaolalla, Víctor; Sola-Morales, Salomé (2019). "Postverdad y discurso intimatorio en Twitter durante el referéndum catalán del 1-O”. (OBS*) Observatorio, v. 13, n. 1, pp. 102-121.

https://doi.org/10.15847/obsOBS13120191356

Hine, Christine (2004). Etnografía virtual. Barcelona: UOC. ISBN: 8497880196

Horeck, Tanya (2014). "\#AskThicke: "Blurred lines", rape culture, and the feminist hashtag takeover". Feminist media studies, v. 14, n. 6, pp. 1105-1107.

https://doi.org/10.1080/14680777.2014.975450

Ibáñez-Fanés, Jordi (ed.) (2017). En la era de la posverdad. 14 ensayos. Barcelona: Calambur. ISBN: 9788483594179

Jackson, Sarah J. (2016). "(Re)Imagining intersectional democracy from black feminism to hashtag activism". Women's studies in communication, v. 39, n. 4, pp. 375-379.

https://doi.org/10.1080/07491409.2016.1226654

Khoja-Moolji, Shenila (2015). "Becoming an 'intimate publics': Exploring the affective intensities of hashtag feminism”. Feminist media studies, v. 15, n. 2, pp. 347-350.

https://doi.org/10.1080/14680777.2015.1008747

Murthy, Dhiraj; Powell, Alison B.; Tinati, Ramine; Anstead, Nick; Carr, Leslie; Halford, Susan J.; Weal, Mark (2016). "Bots and political influence: A sociotechnical investigation of social network capital". International journal of communication, n. 10, pp. 4952-4971.

https://eprints.soton.ac.uk/401577/1/6271-22505-1-PB.pdf

Pariser, Eli (2011). The filter bubble: What the internet is hiding from you. Londres: Penguin. ISBN: 9780241954522

Pérez-Curiel, Concha; García-Gordillo, Mar (2018). “Política de influencia y tendencia fake en Twitter. Efectos postelectorales (21D) en el marco del Procés en Cataluña". El profesional de la información, v. 27, n. 5, pp. 1030-1040.

https://doi.org/10.3145/epi.2018.sep.07

Rattanaritnont Geerajit; Toyoda Masashi; Kitsuregawa, Masaru (2012). "Characterizing topic-specific hashtag cascade in Twitter based on distributions of user influence". In: APWeb'12 Procs of the $14^{\text {th }}$ Asia-Pacific intl conf on web technologies and applications, n. 13, pp. 735-742. ISBN: 9783642292521

https://doi.org/10.1007/978-3-642-29253-8_71

Redondo, Myriam (2018). Verificación digital para periodistas. Manual contra bulos y desinformación internacional. Barcelona: UOC. ISBN: 9788491801290

Rosado-Millán, María-Jesús; García-García, Francisco; Kaplún-Hirsz, Daniel (2014). Guía práctica de técnicas de investigación social. Madrid: Fundación iS+D para la Investigación Social Avanzada. ISBN: 9788494051333

Santander, Pedro (2011). "Por qué y cómo hacer análisis de discurso". Cinta de Moebio: Revista de epistemología de ciencias sociales, n. 41, pp. 207-224.

https://doi.org/10.4067/S0717-554X2011000200006 
Santoveña-Casal, Sonia (2017). "Conversations, debates and affiliation networks on Twitter". The Turkish online journal of educational technology, v. 16, n. 3, pp. 47-59.

https://files.eric.ed.gov/fulltext/EJ1152663.pdf

Shao, Chengcheng; Luca-Ciampaglia, Giovanni; Varol, Onur; Flammini, Alessandro; Menczer, Filippo (2017). "The spread of fake news by social bots".

https://www.andyblackassociates.co.uk/wp-content/uploads/2015/06/fakenewsbots.pdf

Sharma, Sanjay (2012). “Black Twitter? Racial hashtags, networks and contagion”. New formations, n. 78, pp. 46-64.

https://bit.ly/2EZLd4E

https://doi.org/10.3898/NEWF.78.02.2013

Stache, Lara C. (2014). "Advocacy and political potential at the convergence of hashtag activism and commerce". Feminist media studies, v. 15, n. 1, pp. 162-164.

https://doi.org/10.1080/14680777.2015.987429

Van-Dijk, Teun A. (2015). "La multidisciplinariedad del análisis crítico del discurso: Un alegato a favor de la diversidad". En: Wodak, Ruth; Meyer, Michael. Métodos de análisis crítico del discurso. Barcelona: Gedisa, pp. 143-177. ISBN: 9788474329704

http://www.discursos.org/oldarticles/La\%20multidisciplinariedad.pdf

Vosoughi, Soroush; Roy, Deb; Aral, Sinan (2018). "The spread of true and false news online”. Science, v. 359, n. 6380, pp. 1146-1151.

https://doi.org/10.1126/science.aap9559

Williams, Sherri (2015). “Digital defense: Black feminists resist violence with hashtag activism". Feminist media studies, v. 15, n. 2, pp. 341-344.

https://doi.org/10.1080/14680777.2015.1008744

Yang, Guobin (2016). "Narrative agency in hashtag activism: The case of \#BlackLivesMatter". Media and communication, v. 4, n. 4, pp.13-17.

https://doi.org/10.17645/mac.v4i4.692

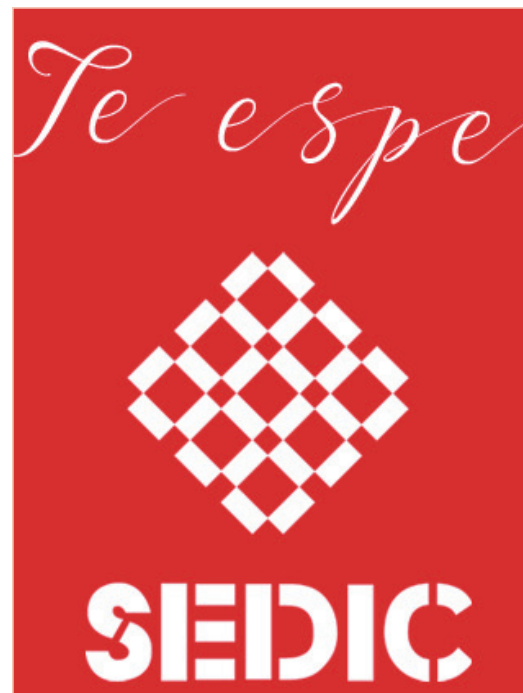

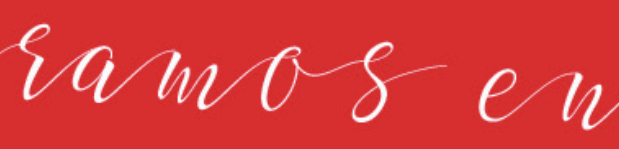

WWW.sedic.es

c/Rodriguez San Pedro 2,

oficina 606. 28015 Madrid

Tfno: +34915934059

secretaria@sedic.es

Sociedad

Española de

Documentación e Información

Científica

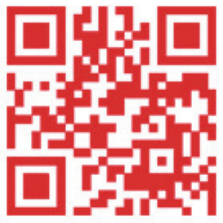

\section{https://twitter.com/SEDIC20}

f https://wwww.facebook.com/AsociacionSEDIC

in https://wwww.linkedin.com/groups?home=\&gid=5060038 